\title{
The Novel 5-Lipoxygenase Inhibitor ABT-761 Attenuates Cerebral Vasospasm in a Rabbit Model of Subarachnoid Hemorrhage
}

\author{
Marcos D. Barbosa, M.D., Adam S. Arthur, M.D., \\ R. Hunter Louis, B.A., Timothy MacDonald, Ph.D., \\ Richard S. Polin, M.D., Christine Gazak, M.P.H., \\ Neal F. Kassell, M.D. \\ Department of Neurological Surgery, Virginia Neurological Institute (MDB, RHL, \\ RSP, NFK), and Department of Chemistry (TM), University of Virginia, Charlottesville, \\ Virginia, and Departments of Neurological Surgery and Family and Preventive \\ Medicine (ASA, CG), University of Utah, Salt Lake City, Utah
}

OBJECTIVE: Eicosanoids have been implicated in the pathogenesis of cerebral vasospasm after subarachnoid hemorrhage (SAH). Leukotrienes, 5-hydroxyperoxyeicosatetraenoic acid, and 5-hydroxyeicosatetraenoic acid are part of this group of substances, resulting from the 5-lipoxygenase activity on arachidonic acid metabolism. This study examined the effects of ABT-761, a new 5-lipoxygenase inhibitor, on cerebral vasospasm in an in vivo rabbit model of SAH.

METHODS: A total of 48 rabbits were assigned to one of six groups: SAH + placebo $(n=8), S A H+A B T-76120$ $\mathrm{mg} / \mathrm{kg}(\mathrm{n}=8), \mathrm{SAH}+\mathrm{ABT}-76130 \mathrm{mg} / \mathrm{kg}(\mathrm{n}=8)$, control + placebo $(\mathrm{n}=8)$, control + ABT-761 $20 \mathrm{mg} / \mathrm{kg}(\mathrm{n}$ $=8)$, and control $+A B T-76130 \mathrm{mg} / \mathrm{kg}(\mathrm{n}=8)$. Drug administration was initiated 30 minutes after induction of SAH and repeated 24 hours later. The animals were killed 48 hours after SAH, using the perfusion-fixation method. The cross sectional areas of basilar artery histological sections were measured by an investigator blinded to the treatment groups of the individual samples.

RESULTS: In placebo-treated animals, the average luminal cross sectional area of the basilar artery was reduced by $68 \%$ after SAH as compared with controls $(P<\mathbf{0 . 0 0 0 1})$. After SAH, the vasospastic response was attenuated in animals treated with 20 or $30 \mathrm{mg} / \mathrm{kg}$ representing a 28 or $35 \%$ reduction, respectively $(P=0.0011$ and $P=0.0038)$.

CONCLUSION: The results demonstrated that ABT-761 is effective in attenuating experimental cerebral vasospasm, indicating that this new drug represents a potential therapeutic agent for the treatment of vasospasm after SAH. (Neurosurgery 49:1205-1213, 2001)

Key words: ABT-761, Arachidonic acid, Cerebral vasospasm, Eicosanoids, Inflammation, Leukotrienes, Subarachnoid hemorrhage

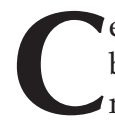

erebral vasospasm is the most important cause of morbidity and mortality in patients surviving subarachnoid hemorrhage (SAH), as it can compromise cerebral hemodynamics and lead to the development of delayed ischemic neurological deficits $(7,18,53)$. The mechanism of cerebral vasospasm is still unclear, but is likely to involve a complex chain of events involving inflammatory processes taking place in the arterial wall $(6,7,15,18,51)$.

The metabolism of arachidonic acid undergoes pathological changes after $\mathrm{SAH}$ and provides substrate for the cyclooxygenase and lipoxygenase pathways. Prostaglandins and thromboxane are produced in the first pathway. Leukotrienes, hydroxyperoxyeicosatetraenoic (HPETE) acid, and hydroxyeicosatetraenoic (HETE) acid result from lipoxygenase activity in the second pathway $(14,21,39,40)$. The products of both pathways are inflammatory mediators and have been shown to have vasoactive properties. 5-lipoxygenase activity is enhanced after an $\mathrm{SAH}$; this increased activity may be significant in the pathogenesis of cerebral vasospasm $(44,54)$. If so, the administration of an inhibitor should ameliorate experimental cerebral vasospasm after SAH.

To test this hypothesis, we evaluated the potential therapeutic value of the new compound ABT-761 after SAHinduced vasospasm in the rabbit model. This compound is a 
potent and selective 5-lipoxygenase inhibitor with extended duration of action. It has a molecular weight of 318.37; the molecular formula is $\mathrm{C}_{16} \mathrm{H}_{15} \mathrm{FN}_{2} \mathrm{O}_{2} \mathrm{~S}$. ABT-761 has been shown to attenuate experimental bronchoconstriction and pulmonary inflammation (2), but has not been tried in the context of cerebral vasospasm.

\section{MATERIALS AND METHODS}

\section{Overview}

Forty-eight male New Zealand White rabbits weighing 3.0 to $4.0 \mathrm{~kg}$ each were assigned to one of six groups. Rabbits in the SAH groups were killed 48 hours after SAH was induced, and those not subjected to SAH were killed 48 hours after the initiation of placebo or ABT-761 administration. Group 1 animals $(\mathrm{SAH}+$ placebo) were subjected to $\mathrm{SAH}$ and given a placebo $(\mathrm{n}=8)$. Group 2 animals (SAH + drug $20 \mathrm{mg} / \mathrm{kg}$ ) were subjected to SAH and given ABT-761 $(n=8)$. Group 3 animals (SAH + drug $30 \mathrm{mg} / \mathrm{kg}$ ) were also subjected to $\mathrm{SAH}$ and given ABT-761 $(\mathrm{n}=8)$. Group 4 animals (control + placebo) were not subjected to SAH and were given a placebo $(\mathrm{n}=8)$. Group 5 animals (control + drug $20 \mathrm{mg} / \mathrm{kg}$ ) were not subjected to SAH but were given ABT-761 $(n=8)$. Group 6 animals (control + drug $30 \mathrm{mg} / \mathrm{kg}$ ) were not subjected to SAH but were given ABT-761 $(n=8)$.

$\mathrm{SAH}$, perfusion-fixation, embedding, and morphometry were performed as described previously and below. All experimental protocols were approved by the University of Virginia Animal Research Committee.

\section{ABT-761 administration}

In Group 1 animals (SAH + placebo), a placebo was administered 30 minutes after hemorrhage and repeated 24 hours later. ABT-761 was administered as an oral suspension in a dose of $20 \mathrm{mg} / \mathrm{kg}$ or $30 \mathrm{mg} / \mathrm{kg}$ in $4 \mathrm{ml} / \mathrm{kg}$ of vehicle (methylcellulose $0.2 \%$ in water). In Group 2 and 3 animals $(\mathrm{SAH}+\mathrm{drug})$, ABT-761 was given 30 minutes after hemorrhage and repeated 24 hours later. Group 5 and 6 animals (control + drug) received ABT-761 at the start of the study period and then 24 hours later. Group 4 animals (control + placebo) received a placebo (methylcellulose $0.2 \%$ in water) on the same schedule.

\section{Induction of SAH}

Animals in Groups 1, 2, and 3 were anesthetized with an intramuscular injection of a mixture of ketamine $(40 \mathrm{mg} / \mathrm{kg}$ ) and xylazine $(8 \mathrm{mg} / \mathrm{kg})$ and endotracheally intubated. The central ear artery was cannulated to obtain $5 \mathrm{ml}$ of autologous arterial blood. A 23-gauge butterfly needle was inserted percutaneously into the cisterna magna, and $5 \mathrm{ml}$ of autologous blood was injected during a 20-second period. To facilitate the settling of blood in the basal cisterns, the animals were positioned with their heads down for 20 minutes. They were monitored closely for respiratory distress and, if necessary, placed on a ventilator until spontaneous respiration resumed. The animals were extubated and returned to their cages when fully awake; during the next 48 hours, they were allowed free access to food and water and were observed closely for adequate food intake and for any possible neurological deficits.

\section{Perfusion-fixation}

Animals were anesthetized and intubated at the 48th hour of the study period as described above, and cerebrospinal fluid (CSF) was collected from the cisterna magna for determination of the ABT-761 concentration. The animals were then paralyzed with pancuronium bromide $(0.3 \mathrm{mg} / \mathrm{kg})$ and mechanically ventilated. The central ear artery was cannulated for recording arterial pressure via an arterial line transducer. Arterial blood gas tension was measured and ventilation parameters adjusted accordingly to maintain arterial $\mathrm{pO}_{2}$ and $\mathrm{pCO}_{2}$ within the physiological range. After satisfactory respiratory parameters under anesthesia were established, the thorax was opened and a cannula was placed in the aorta via the left ventricle. The right atrial appendage was opened and the descending thoracic aorta clamped. The vascular system was perfused with $300 \mathrm{ml}$ of Hanks' balanced salt solution (Sigma Chemical Co., St. Louis, MO) ( $\mathrm{pH} 7.4$ at $37^{\circ} \mathrm{C}$ ) followed by $500 \mathrm{ml}$ of $1 \%$ paraformaldehyde and $1.5 \%$ glutaraldehyde fixative in Hanks' balanced salt solution. Perfusion was performed at a pressure of $75 \mathrm{~mm} \mathrm{Hg}$ in all groups. After perfusion-fixation, the brainstem was removed, placed in the same fixative solution, and stored at $4^{\circ} \mathrm{C}$ overnight. Animals that showed incomplete subarachnoid clot or had residual blood in the vasculature suggesting an inadequate perfusion were excluded from the study at this point. Clot grading and exclusion were performed by an investigator blinded to the treatment group of the individual animals.

\section{Embedding}

After fixation, the basilar artery was removed from the brainstem and the proximal third of the vessel was cut into segments $2 \mathrm{~mm}$ in length. The tissue samples were washed several times in $0.1 \mathrm{~mol} / \mathrm{L}$ phosphate buffer, postfixed in $1 \%$ osmium tetroxide in $0.1 \mathrm{~mol} / \mathrm{L}$ phosphate buffer ( $\mathrm{pH} 7.4$ ) for 1 hour at room temperature, and washed again in phosphate buffer. The tissue was dehydrated through a series of graded ethyl alcohol solutions followed by propylene oxide. The samples were placed in a 1:1 mixture of propylene oxide and epoxy resin overnight; the next day, they were flat embedded in $100 \%$ epoxy resin and allowed to polymerize at $60^{\circ} \mathrm{C}$ for 48 hours. Cross sections of the basilar artery ( $0.5 \mu \mathrm{m}$ thick) were cut on a Reichert Ultracut E ultramicrotome (Vienna, Austria) and mounted on glass slides.

\section{Morphometry}

Morphometric measurements of three randomly selected arterial cross sections from each animal were performed using the Image 1 Analysis System (Universal Imaging, West Chester, PA). Basilar artery cross sectional area was measured by an investigator blinded to the treatment groups of the individual arteries. The luminal area was calculated from the perimeter of the internal elastic lamina and the area contained within the boundaries of the internal elastic lamina. Three measurements were taken from randomly selected cross sec- 
tions of each basilar artery. The luminal area for each basilar artery was obtained by averaging these three measurements.

\section{Determination of ABT-761 CSF concentration}

CSF samples were collected at the 48th hour (before perfusion-fixation) and centrifuged; the CSF was removed and stored frozen until assayed. The frozen samples were thawed, two volumes of methanol were added, and precipitated CSF proteins were removed by centrifugation. Supernatants were injected directly onto a C18 reversed-phase column (Adsorbo sphere HL 7- $\mu \mathrm{m}$ column) and underwent chromatography with a mobile phase composed of $55 \%$ acetonitrile containing $10 \mathrm{mmol} / \mathrm{L}$ of acetohydroxamic acid and 8 $\mathrm{mmol} / \mathrm{L}$ of triethylamine acetate $(\mathrm{pH}$ 6.5) at a flow rate of 1 $\mathrm{ml} / \mathrm{min}$. Peaks corresponding to ABT-761 were quantified by ultraviolet absorbance at $260 \mathrm{~nm}$ using an external calibration curve.

\section{Statistical analysis}

A Kruskal-Wallis one-way analysis of variance was performed on the entire data set of morphometric measurements. Pairwise multiple comparison post hoc analysis was performed using the Bonferroni-Dunn method. Partial correlation coefficients were performed on CSF ABT-761 concentration values by treatment groups.

\section{RESULTS}

The cross sectional areas of the basilar artery of individual animals are shown in Table 1, and a graphical representation of the mean values for each group is presented in Figure 1. Figure 2 shows photographic examples of basilar artery cross sections from Group 1 (SAH + placebo) and $2(\mathrm{SAH}+20$

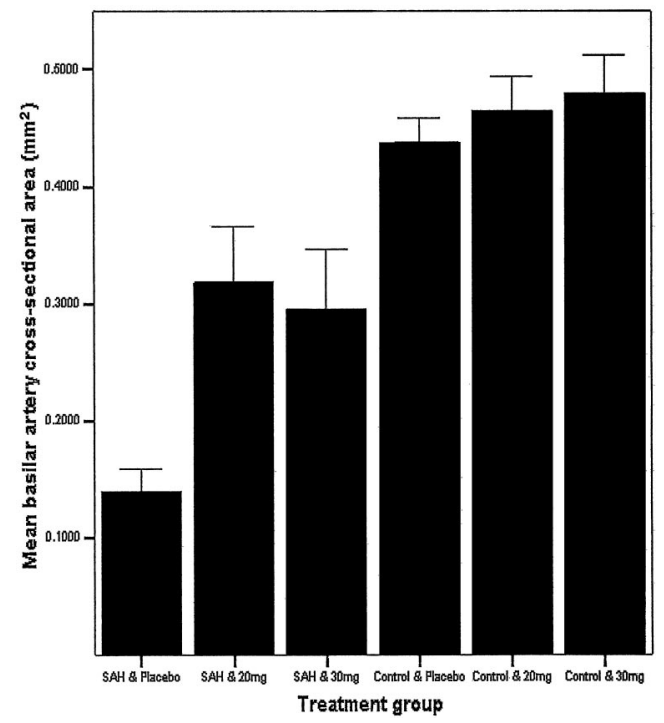

FIGURE 1. Graph depicting the effect of ABT-761 treatment on arterial narrowing induced by $\mathrm{SAH}$. The values represent the mean \pm standard error for each treatment group.

$\mathrm{mg} / \mathrm{kg}$ ) animals. A Kruskal-Wallis one-way analysis of variance was performed on the entire data set, which passed the normality test $(P=0.501)$ and the equal variance test $(P=$ $0.097)$ and demonstrated statistical significance at the level of $P<0.01$. SAH elicited a reduction in vascular area of $68 \%$ in the placebo-treated animals (Group 1) as compared with controls (Group 4). In contrast, the reduction in cross sectional area in animals treated with ABT-761 was $28 \%$ in Group 2 and $35 \%$ in Group 3. Although data from Group 2 represent a

TABLE 1. Cross Sectional Area of Basilar Arteries of Individual Animals $\left(\mathrm{mm}^{2}\right)^{a}$

\begin{tabular}{|c|c|c|c|c|c|c|}
\hline & $\begin{array}{c}\text { Group } 1 \\
\text { SAH + Placebo }\end{array}$ & $\begin{array}{c}\text { Group } 2 \\
\text { SAH + D20 }\end{array}$ & $\begin{array}{c}\text { Group } 3 \\
\text { SAH + D30 }\end{array}$ & $\begin{array}{c}\text { Group } 4 \\
\text { Control + } \\
\text { Placebo }\end{array}$ & $\begin{array}{c}\text { Group } 5 \\
\text { Control }+ \text { D20 }\end{array}$ & $\begin{array}{c}\text { Group } 6 \\
\text { Control + D30 }\end{array}$ \\
\hline & 0.124 & 0.250 & 0.395 & 0.356 & 0.416 & 0.669 \\
\hline & 0.127 & 0.371 & 0.403 & 0.462 & 0.414 & 0.434 \\
\hline & 0.239 & 0.239 & 0.180 & 0.424 & 0.496 & 0.489 \\
\hline & 0.076 & 0.460 & 0.305 & 0.357 & 0.525 & 0.433 \\
\hline & 0.129 & 0.073 & 0.139 & 0.505 & 0.536 & 0.437 \\
\hline & 0.081 & 0.281 & 0.077 & 0.485 & 0.482 & 0.374 \\
\hline & 0.199 & 0.380 & 0.492 & 0.492 & 0.546 & 0.457 \\
\hline & 0.144 & 0.490 & 0.302 & 0.418 & 0.302 & 0.545 \\
\hline Mean $\pm S D$ & $0.140 \pm 0.553^{b}$ & $0.318 \pm 1.355^{c}$ & $0.287 \pm 1.438^{d}$ & $0.437 \pm 0.586$ & $0.465 \pm 0.828^{e}$ & $0.480 \pm 0.909^{f}$ \\
\hline
\end{tabular}

${ }^{\text {a } S A H, ~ s u b a r a c h n o i d ~ h e m o r r h a g e ; ~ D 20, ~ A B T-761 ~} 20$ mg/kg; D30, ABT-761 30 mg/kg; SD, standard deviation.

${ }^{b}$ Different from Group $4(P<0.0001)$.

${ }^{c}$ Different from Group $1(P=0.0011)$.

${ }^{d}$ Different from Group $1(P=0.0038)$, not different from Group $2(P=0.6522)$.

e Not different from Groups $4(P=0.5935)$ and $6(P=0.7668)$.

${ }^{f}$ Not different from Group $4(P=0.4077)$. 

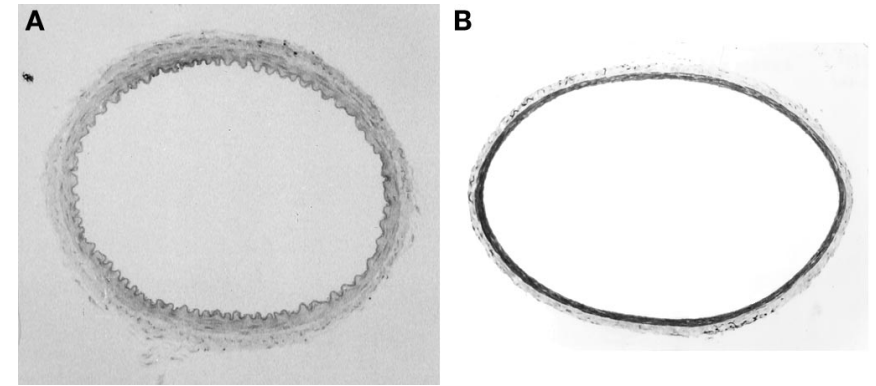

FIGURE 2. Photomicrographs of representative cross sections of the basilar artery corresponding to Group 1 (SAH + placebo) (A) and Group 2 (SAH + drug $20 \mathrm{mg} / \mathrm{kg})(B)$.

statistically significant reduction in the vasospastic response observed as compared with Group $1(P=0.0011)$, data from Group 3 fell just short of statistical significance at $P=0.0038$, with significance represented by $P<0.0033$. It is noteworthy that the values obtained for animals treated with ABT-761 but not subjected to SAH (Groups 5 and 6) did not differ significantly from the untreated control animals $(P=0.5995$ and $P$ $=0.4077)$, indicating that the drug is not a simple vasodilator.

Table 2 shows the concentration of CSF ABT-761, verifying that the drug appears in the subarachnoid space. Partial correlation coefficients between treatment groups were not statistically significant. Figure 3 displays the mean CSF ABT-761 concentration by treatment group. Figure 4 is a scatterplot of CSF ABT-761 concentration versus basilar artery cross sectional area.

\section{DISCUSSION}

Cerebral vasospasm remains a major complication after an $\mathrm{SAH}$ and, despite intensive studies, its precise mechanism is not yet fully understood. Several putative spasmogens have been shown to be active in the development of cerebral vaso-

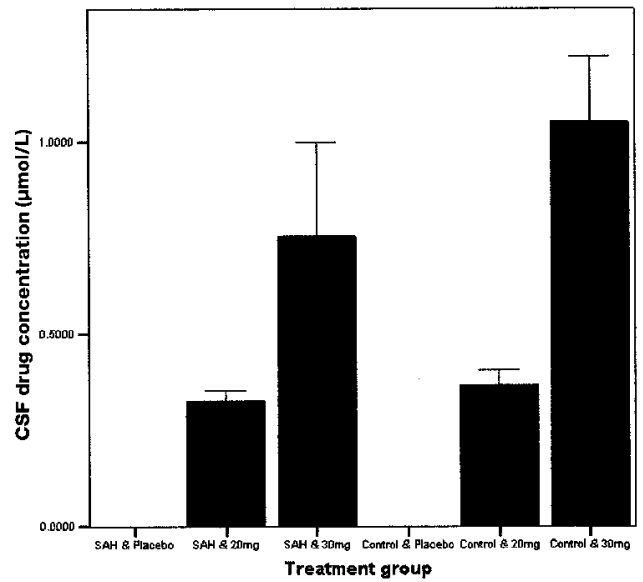

FIGURE 3. Bar graph depicting the concentration of ABT761 in CSF by the treatment group, demonstrating drug penetration in the CSF space.

spasm $(7,15,18,53)$. It has been established that an inflammatory reaction occurs after SAH $(13,57)$. This local process takes place in the arterial wall and in the subarachnoid space and may induce structural changes within the arterial wall that contribute to the development of cerebral vasospasm (6, $15,18,26-28,34,51)$.

It has been proposed that hemoglobin released from the subarachnoid blood clot induces the production of arachidonic acid metabolites, inflammatory mediators that have direct vasoactive effects (47). Several studies reported the possible involvement of arachidonic acid metabolism products in the development of vasospasm. Initially, eicosanoids produced by the activity of cyclooxygenase-prostaglandins, thromboxane, and prostacyclin were the subject of scrutiny in the vasospasm literature $(7,9,24,35,41,43,52,56)$. More recently, other eicosanoids resulting from the lipoxygenase pathway, such as leukotrienes, HPETE acid, and HETE acid,

TABLE 2. Cerebrospinal Fluid ABT-761 Concentrations ( $\mu \mathrm{mol} / \mathrm{L})^{a}$

\begin{tabular}{|c|c|c|c|c|c|c|}
\hline & $\begin{array}{l}\text { Group } 1 \\
\text { SAH }+ \\
\text { Placebo }\end{array}$ & $\begin{array}{c}\text { Group } 2 \\
\mathrm{SAH}+20 \mathrm{mg}\end{array}$ & $\begin{array}{c}\text { Group } 3 \\
\text { SAH }+30 \mathrm{mg}\end{array}$ & $\begin{array}{c}\text { Group } 4 \\
\text { Control }+ \text { Placebo }\end{array}$ & $\begin{array}{c}\text { Group } 5 \\
\text { Control }+20 \mathrm{mg}\end{array}$ & $\begin{array}{c}\text { Group } 6 \\
\text { Control }+30 \mathrm{mg}\end{array}$ \\
\hline & 0.00 & 0.31 & 0.42 & 0.00 & 0.25 & 0.91 \\
\hline & 0.00 & 0.31 & 0.35 & 0.00 & 0.25 & 0.66 \\
\hline & 0.00 & 0.29 & 0.52 & 0.00 & 0.53 & 0.70 \\
\hline & 0.00 & 0.23 & 0.21 & 0.00 & 0.36 & 0.78 \\
\hline & 0.00 & 0.40 & 0.25 & 0.00 & 0.35 & 1.69 \\
\hline & 0.00 & 0.42 & 1.97 & 0.00 & 0.36 & 0.92 \\
\hline & 0.00 & & 0.57 & 0.00 & 0.47 & 1.70 \\
\hline & & & 1.75 & & & \\
\hline Mean & 0.00 & 0.32 & 0.75 & 0.00 & 0.36 & 1.05 \\
\hline
\end{tabular}

\footnotetext{
${ }^{a} \mathrm{SAH}$, subarachnoid hemorrhage; $20 \mathrm{mg}$, ABT-761 $20 \mathrm{mg} / \mathrm{kg} ; 30 \mathrm{mg}$, ABT-761 $30 \mathrm{mg} / \mathrm{kg}$.
} 


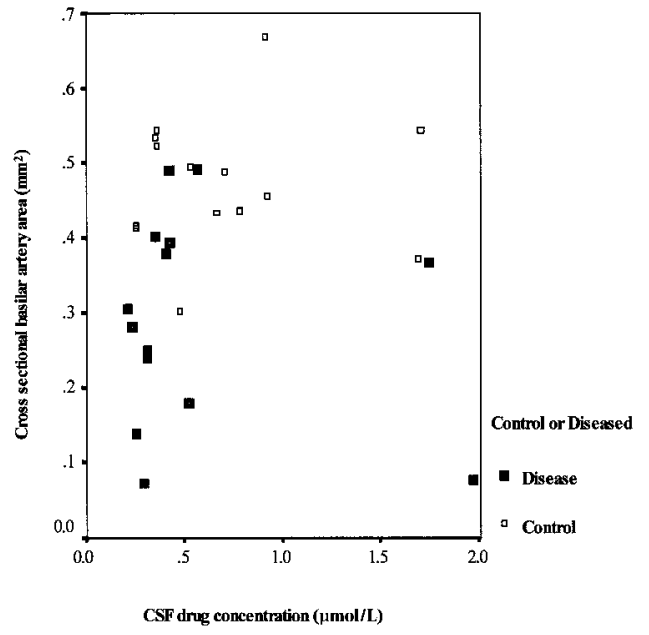

FIGURE 4. Graph showing the concentration of ABT-761 in CSF versus the basilar artery cross sectional area. A trend toward segregation of $\mathrm{SAH}$ versus control animals can be seen.

have received more interest $(10,19,20,23,25,33-35,44,48-50$, $54,59)$.

Leukotrienes, HPETE acid, and HETE acid are formed by the activity of 5-lipoxygenase. This enzyme catalyzes both the transformation of arachidonic acid in 5-HPETE acid and of 5-HPETE acid in leukotriene $A_{4}$, the common precursor of leukotrienes. Leukotriene $\mathrm{A}_{4}$ produces leukotriene $\mathrm{B}_{4}$ and leukotriene $\mathrm{C}_{4}$; leukotriene $\mathrm{C}_{4}$ is transformed into leukotriene $\mathrm{D}_{4}$ and leukotriene $\mathrm{E}_{4}(14,21,39,40)$. Leukotrienes, HPETE acid, and HETE acid have large-action variabilities that include vasoconstrictor properties, prostacyclin synthesis inhibition, platelet aggregation inhibition, promotion of neutrophil and eosinophil chemotaxis, activation of lymphocytes, increases in vascular permeability, and the induction of enzyme release.

Several studies have shown that leukotrienes and other lipoxygenase products have vasoconstrictor properties on vascular beds $(29,32,36)$, including cerebral arterial beds both in vitro and in vivo $(17,30,36,46)$. These substances are produced in the brain by cerebral arteries and by neurons ( 8 , $10,17,19,23,30,44,59)$.

The production of leukotrienes is elevated in SAH (9-11, 19, $20,23,25,33,34,44,45,50,55,59)$, and CSF levels are related to the presence of vasospasm $(12,20,25,45,55)$. The subarachnoid blood clot itself produces leukotrienes $(34,59)$. In addition, leukocytes released from the blood clot or infiltrating the arterial wall produce leukotrienes in a self-maintaining manner, allowing leukotrienes to exert their vasoconstrictor effect for a longer period of time $(9,10,23,25,39)$. 5-lipoxygenase activity is also enhanced in SAH (44).

It can be assumed that the development of cerebral vasospasm is a complex problem, with many systems interacting with various components of the blood, vessel wall, and subarachnoid space. SAH stimulates arachidonic acid metabolism, and the leukotrienes, HPETE acid, and HETE acid produced in the 5-lipoxygenase pathway may contribute to the induction of cerebral vasospasm via a variety of mechanisms. These include a direct vasoconstrictor effect on cerebral arteries as a result of the following: activation of phospholipase C, which induces intracellular calcium mobilization; the direct action of cysteinyl leukotrienes, HPETE acid, and HETE acid; the stimulation of free radical production by the reduction of 5-HPETE acid to 5-HETE acid; the antagonism of the vasodilatory effects of prostacyclin by the activity of leukocytes attracted by leukotriene $\mathrm{B}_{4}$; and the promotion of an inflammatory reaction in the arterial wall and in the subarachnoid space. The inflammatory response resulting from the leukocyte infiltration of the arterial wall further promotes the release of lipoxygenase products and modifies the normal structure of the vessel, possibly sustaining a self-maintaining reaction that leads to chronic vasospasm (10).

Although the cyclooxygenase pathway may also be implicated in the pathogenesis of cerebral vasospasm through inhibition of prostacyclin synthesis and an increase in prostaglandin and thromboxane production, it seems unlikely that an imbalance between prostacyclins and prostaglandins or thromboxanes $(3,12,24,35,41)$ is the key factor in the pathogenesis of cerebral vasospasm $(7,11,22,43)$. The products of 5-lipoxygenase may play a more important role than the products of cyclooxygenase in the development of cerebral vasospasm after SAH.

Despite recognition of the potential importance of lipoxygenase products in cerebral vasospasm, their precise role has not been defined. The development of new agents capable of interfering with the synthesis or action of these potent substances may help to more fully explore this issue. Lipoxygenase synthesis inhibitors $(1,4,5,8,16,31,37,38,42,58,60)$ and leukotriene receptor antagonists $(17,20,29,31,36,38)$ have been shown to inhibit the action of leukotrienes and/or HPETE and HETE acids. In a few cases, this therapeutic strategy has shown some potential to prevent the development of delayed cerebral vasospasm after experimental SAH $(20,49,58)$.

To test the hypothesis that the 5-lipoxygenase pathway plays a significant role in the development of cerebral vasospasm, we studied the effect of ABT-761 ([R]-N-[3-\{5-\{4-fluorophenylmethyl\}thien2yl\}-1-methyl-2-propynyl]-N-hydroxyurea) in an experimental model of SAH-induced cerebral vasospasm. This agent is a potent and selective inhibitor of leukotriene formation both in vitro and in vivo. ABT-761 is a second-generation 5-lipoxygenase inhibitor, is more potent than other $N$-hydroxyureas containing 5-lipoxygenase inhibitors, and has excellent pharmacokinetic characteristics $(2,4)$. The precise mechanism by which $\mathrm{N}$-hydroxyurea compounds inhibit 5-lipoxygenase activity has not yet been defined, but the fact that this inhibition is reversible and independent of preincubation time indicates that there is not a covalent interaction of the compound with the enzyme. It is possible that the hydroxamic acid moiety ( $\mathrm{N}$-hydroxyurea) complexes with the iron atom at the active site of the enzyme. It selectively blocks the formation of 5-HPETE and its transformation in leukotriene $\mathrm{A}_{4}$ and, consequently, inhibits the synthesis of all other leukotrienes and 5-HETE acid (1,4). It has a weakly 
inhibitory effect on other eicosanoid-metabolizing enzymes, such as 12- and 15-lipoxygenase and cyclooxygenase (2). The use of this potent and specific 5-lipoxygenase inhibitor is therefore theoretically capable of attenuating the vascular effects of the 5-lipoxygenase products of arachidonic acid metabolism.

It is interesting that a greater effect is noted in the group treated with $20 \mathrm{mg} / \mathrm{kg}$ of ABT-761 than in the group treated with $30 \mathrm{mg} / \mathrm{kg}$, although the difference between the difference was not statistically significant. The cross sectional area of the basilar artery in the group treated with $30 \mathrm{mg} / \mathrm{kg}$ (Group 3) certainly shows a strong trend toward attenuation of vasospasm. ABT-761 is a highly selective inhibitor of 5-lipoxygenase, but it is possible that the lessened effect at a higher dosage indicates saturation of available 5-lipoxygenase with a spillover inhibition of other arachidonic acid pathway catalysts, causing a corresponding decrease in the production of endogenous vasodilatory substances. Further studies are planned to elucidate the maximally effective dosage of the compound and to establish a dose-response curve.

CSF ABT-761 concentration values are displayed in Table 2 and Figure 3. Correlation coefficients among the treatment groups did not show statistical significance; however, we think that it is important that drug penetration into the CSF space is demonstrated. The range of CSF ABT-761 concentrations were much greater in Groups 3 and $6(\mathrm{SAH}+30 \mathrm{mg} / \mathrm{kg}$ and control $+30 \mathrm{mg} / \mathrm{kg}$, respectively) than in Groups 2 and $5(\mathrm{SAH}+20 \mathrm{mg} / \mathrm{kg}$ and control $+20 \mathrm{mg} / \mathrm{kg}$, respectively). This trend toward a greater variability of CSF concentration may represent a saturation or clearance effect. This, coupled with the lessened effect on basilar artery area in Group 3, raises some interesting pharmacodynamic issues for future study.

Figure 4 depicts the concentration of CSF ABT-761 plotted against the cross sectional area of the basilar artery. A trend toward segregation of SAH versus control animals is apparent. The concentration of ABT-761 in control animals is highly variable, although the cross sectional area of the basilar artery remains fairly consistent. Conversely, the concentration of ABT-761 in SAH animals is usually less than $0.3 \mu \mathrm{mol} / \mathrm{L}$; however, the cross sectional area of the basilar artery is highly variable. Variability in the cross sectional area is expected in SAH groups; not all hemorrhaged animals achieve the same degree of vasospasm. The greater degree of variability in drug concentration among control animals may indicate a trend toward variable drug utilization in the SAH animals than in the control animals.

The results of this study demonstrate that ABT-761, when administered orally once a day for 48 hours, can be of value in reducing the vasospastic arterial response after SAH. Although both dosages studied achieved statistical significance, more studies are needed to establish the dose-response curve and to define the maximally effective dose. It is also necessary to delineate the potential side effects with short-term administration and to clarify the window of therapeutic benefit as well as the efficacy of other administration routes.

This study represents a test of concept and establishes the potential utility of this family of compounds for this application. Primate studies are needed to clarify whether second- generation 5-lipoxygenase inhibition has a potential role in the treatment of clinical cerebral vasospasm.

\section{ACKNOWLEDGMENTS}

We thank Sarah Hudson for photography and support, Jan Redick and Bonnie Sheppard for help in preparing histological sections, and Randy Bell from Abbott Laboratories for the donation of the compound and for performing its CSF concentration determination. This work was supported in part by Fundação Calouste Gulbenkian (to MDB).

Received, May 16, 2000.

Accepted, June 28, 2001.

Reprint requests: Neal F. Kassell, M.D., Department of Neurological Surgery, University of Virginia Health Sciences Center, Box 212, Charlottesville, VA 22908. Email: nfk8g@virginia.edu

\section{REFERENCES}

1. Bell RL, Bouska JB, Malo PE, Lanni C, Harris RR, Otis ER, Steward AO, Brooks DW, Carter GW: Optimization of the potency and duration of action of N-hydroxyurea 5-lipoxygenase inhibitors. J Pharmacol Exp Ther 272:724-731, 1995.

2. Bell RL, Harris RR, Malo PE, Bouska JB, Shaughnessy TK, Hulkower KI, Brooks CDW, Carter GW: ABT-761 attenuates bronchoconstriction and pulmonary inflammation in rodents. J Pharmacol Exp Ther 280:1366-1373, 1997.

3. Boullin DJ, Bunting S, Blaso WP, Hunt TM, Moncada S: Responses of human and baboon arteries to prostaglandin endoperoxides and biologically generated and synthetic prostacyclin: Their relevance to cerebral arterial spasm in man. Br J Clin Pharmacol 7:139-147, 1979.

4. Brooks CDW, Steward AO, Basha A, Bhatia P, Rayajcek JD, Martin JH, Graig RA, Kolasa T, Bouska JB, Lanni C, Harris RR, Malo PE, Carter PE, Bell RL: (R)-( + )N-[5-[(4-Fluorophenylmethyl]-2thenyl]-1-methyl-2-propynyl]-N-hydroxyurea (ABT-761), a second generation 5-lipoxygenase inhibitor. J Med Chem 38:47684775, 1995.

5. Carter GW, Young PR, Albert DH, Bouska J, Dyer R, Bell RL, Summers JB, Brooks DW: 5-lipoxygenase inhibitory activity of Zileuton. J Pharmacol Exp Ther 256:929-937, 1991.

6. Chyatte D, Rush N, Sundt TM Jr: Prevention of chronic experimental cerebral vasospasm with ibuprofen and high-dose methylprednisolone. J Neurosurg 59:925-932, 1983.

7. Cook DA: Mechanisms of cerebral vasospasm in subarachnoid haemorrhage. Pharmacol Ther 66:259-284, 1995.

8. Dembinska-Kiec A, Simmet T, Peskar BA: Formation of leukotriene $\mathrm{C}_{4}$-like material by rat brain tissue. Eur J Pharmacol 99:57-62, 1984.

9. Gaetani P, Marzatico F, Rodriguez y Baena R: Ex vivo release of eicosanoids after aneurysmal subarachnoid hemorrhage: A preliminary experience in humans. Acta Neurol Scand 86:184-189, 1992.

10. Gaetani $P$, Marzatico F, Rodriguez y Baena R, Pacchiarini L, Vigan T, Grignani G, Crivellari MT, Benzi G: Arachidonic acid metabolism and pathophysiologic aspects of subarachnoid hemorrhage in rats. Stroke 21:328-332, 1990.

11. Gaetani P, Rodriguez y Baena R, Paoletti P: Role of blood volume on eicosanoids in cerebrospinal fluid. Neurosurgery 25:143-144, 1989. 
12. Gaetani P, Rodriguez y Baena R, Silvani V, Rainoldi F, Paoletti P: Prostacyclin and vasospasm in subarachnoid hemorrhage from ruptured intracranial aneurysms. Acta Neurol Scand 73:33-38, 1986.

13. Hammes EM Jr: Reaction of the meninges to blood. Arch Neurol Psychiatry 52:505-514, 1944.

14. Henderson WR Jr: The role of leukotrienes in inflammation. Ann Intern Med 121:684-697, 1994.

15. Heros RC, Zervas NT, Varsos V: Cerebral vasospasm after subarachnoid hemorrhage: An update. Ann Neurol 14:599-608, 1983.

16. Israel E, Dermarkarian R, Rosemberg M, Sperling R, Taylor G, Rubin P: The effects of a 5-lipoxygenase inhibitor on asthma induced by cold, dry air. N Engl J Med 323:1740-1744, 1990.

17. Jancar S, Schulz R, Krueger C, Cook DA: Mechanisms of arachidonic acid-induced contractions of canine cerebral arteries. Eur J Pharmacol 136:345-352, 1987.

18. Kassell NF, Sasaki T, Colohan ART, Nazar G: Cerebral vasospasm following aneurysmal subarachnoid hemorrhage. Stroke 16:562572, 1985.

19. Kiwak KJ, Moskowitz MA, Levine L: Leukotriene production in gerbil brain after ischemic insult, subarachnoid hemorrhage, and concussive injury. J Neurosurg 62:865-869, 1985.

20. Kobayashi H, Ide H, Handa Y, Aradachi H, Arai Y, Kubota T: Effect of leukotriene antagonist on experimental delayed cerebral vasospasm. Neurosurgery 31:550-556, 1992.

21. Lewis RA, Austen KF: The biologically active leukotrienes: Biosynthesis, metabolism, receptors, functions and pharmacology. J Clin Invest 73:889-897, 1984.

22. Macdonald RL, Weir BK: Cerebral vasospasm and free radicals. Free Radic Biol Med 16:633-643, 1994.

23. Minami N, Tani E, Yokota M, Maeda Y, Yamaura I: Immunohistochemistry of leukotriene $\mathrm{C} 4$ in experimental cerebral vasospasm. Acta Neuropathol (Berl) 81:401-407, 1991.

24. Nosko M, Schulz R, Weir B, Cook DA, Phil D, Grace M: Effects of vasospasm on levels of prostacyclin and thromboxane $\mathrm{A}_{2}$ in cerebral arteries of the monkey. Neurosurgery 22:45-50, 1988.

25. Paoletti P, Gaetani P, Grignani G, Pacchiarini L, Silvani V, Rodriguez y Baena R: CSF leukotriene $\mathrm{C}_{4}$ following subarachnoid hemorrhage. J Neurosurg 69:488-493, 1988.

26. Peerless SJ, Kassell NF, Komatsu K, Hunter IG: Cerebral vasospasm: Acute proliferative vasculopathy? Part II-Morphology, in Wilkins RH (ed): Cerebral Arterial Spasm. Baltimore, Williams \& Wilkins, 1980, pp 88-96.

27. Peterson JW, Kwun BD, Hackett JD, Zervas NT: The role of inflammation in experimental cerebral vasospasm. J Neurosurg 72:767-774, 1990.

28. Peterson JW, Kwun BD, Teramura A, Hackett JD, Morgan JA, Nishizawa S, Bun T, Zervas NT: Immunological reaction against the aging human subarachnoid erythrocyte: A model for the onset of cerebral vasospasm in subarachnoid hemorrhage. J Neurosurg 71:718-726, 1989.

29. Piomelli D, Feinmark SJ, Cannon PJ: Leukotriene biosynthesis by canine and human coronary arteries. J Pharmacol Exp Ther 241: 763-770, 1987.

30. Piper PJ, Stanton AWB: Leukotrienes and the intracranial circulation. Adv Prostaglandin Thromboxane Leukot Res 15:333-337, 1985.

31. Piper PJ, Letts LG, Galton SA: Generation of a leukotriene-like substance from porcine vascular and other tissues. Prostaglandins 25:591-599, 1983.

32. Piper PJ, Stanton AWB, McLeod LJ: The actions of leukotriene $\mathrm{C}_{4}$ and $\mathrm{D}_{4}$ in the porcine renal vascular bed. Prostaglandins 29:6173, 1985.
33. Rodriguez y Baena R, Gaetani P, Grignani G, Pacchiarini L, Vigano T, Scalabrini DR, Silvani V, Folco G, Paoletti P: Role of arachidonate metabolites in the genesis of cerebral vasospasm. Adv Prostaglandin Thromboxane Leukot Res 17:938-942, 1987.

34. Rodriguez y Baena R, Gaetani P, Paoletti P: A study on cisternal CSF levels of arachidonic acid metabolites after aneurysmal subarachnoid hemorrhage. J Neurol Sci 84:329-335, 1987.

35. Rodriguez y Baena R, Gaetani P, Silvani V, Vigano T, Crivellari MT, Paoletti P: Cisternal and lumbar CSF levels of arachidonate metabolites after subarachnoid hemorrhage: An assessment of the biochemical hypothesis of vasospasm. Acta Neurochir (Wien) 84:129-135, 1987.

36. Rosenblum WI: Constricting effect of leukotrienes on cerebral arterioles of mice. Stroke 16:262-265, 1985.

37. Rubin P, Dubé L, Braeckman R, Swanson L, Hansen R, Albert D: Pharmacokinetics, safety, and ability to diminish leukotriene synthesis by Zileuton, an inhibitor of 5-lipoxygenase. Agents Actions Suppl 35:103-116, 1991.

38. Sala A, Rossoni G, Buccellati C, Berti F, Folco G, Maclouf J: Formation of sulphidopeptide-leukotrienes by cell-cell interaction causes coronary vasoconstriction in isolated, cell-perfused heart of rabbit. Br J Pharmacol 110:1206-1212, 1993.

39. Samuelsson B: Leukotrienes: Mediators of immediate hypersensitivity reactions and inflammation. Science 220:568-575, 1983.

40. Samuelsson B, Dahlén S-V, Lindgren JA, Rouzer CA, Shernan CN: Leukotrienes and lipoxins: Structures, biosynthesis, and biological effects. Science 237:1171-1176, 1987.

41. Sasaki T, Murota S-I, Wakai S, Asano T, Sano K: Evaluation of prostaglandin biosynthetic activity in canine basilar artery following subarachnoid injection of blood. J Neurosurg 55:771-778, 1981.

42. Schulz R, Jancar S, Cook D: Cerebral arteries can generate 5- and 15-hydroxyeicosatetraenoic acid from arachidonic acid. Can J Physiol Pharmacol 68:807-813, 1990.

43. Seifert V, Stolke D, Kunz U, Resch K: Influence of blood volume on cerebrospinal fluid levels of arachidonic acid metabolites after subarachnoid hemorrhage: Experimental study on the pathogenesis of cerebral vasospasm. Neurosurgery 23:313-321, 1988.

44. Shimizu T, Watanabe T, Asano T, Seyama Y, Takakura K: Activation of the arachidonate 5-lipoxygenase pathway in the canine basilar artery after experimental subarachnoidal hemorrhage. J Neurochem 51:1126-1131, 1988.

45. Suzuki N, Nakamura T, Imabayashi S, Ishikawa Y, Sasaki T, Asano T: Identification of 5-hydroxy eicosatetraenoic acid in cerebrospinal fluid after subarachnoid hemorrhage. J Neurochem 41:1186-1189, 1983.

46. Tagari $\mathrm{P}$, du Boulay GH, Aitken V, Boullin D: Leukotriene $\mathrm{D}_{4}$ and the cerebral vasculature in vivo and in vitro. Prostaglandins Leukot Med 11:228-297, 1983.

47. Toda N: Mechanisms of contracting action of oxyhemoglobin in isolated monkey and dog cerebral arteries. Am J Physiol 258[Suppl 1]:H57-H63, 1990.

48. Watanabe T, Asano T, Shimizu T: Arachidonic acid lipoxygenase products participate in the pathogenesis of delayed cerebral ischemia, in Bazan NG, Braquet P, Ginsberg MD (eds): Advances in Neurochemistry. New York, Plenum Press, 1992, pp 139-159.

49. Watanabe T, Asano T, Shimizu T, Seyama Y, Takakura K: Participation of lipoxygenase products from arachidonic acid in the pathogenesis of cerebral vasospasm. J Neurochem 50:1145-1150, 1988. 
50. Weir B: The pathophysiology of cerebral vasospasm. Br J Neurosurg 9:375-390, 1995.

51. Weir BKA, Okwuasaba FK, Cook DA, Krueger CA: Pharmacology of vasospasm: Effects of various agents including blood on isolated cerebral arteries, in Wilkins RH (ed): Cerebral Arterial Spasm. Baltimore, Williams \& Wilkins, 1980, pp 237-243.

52. White RP, Robertson JT: Comparison of piroxicam, meclofenamate, ibuprofen, aspirin, and prostacyclin efficacy in a chronic model of cerebral vasospasm. Neurosurgery 12:40-46, 1983.

53. White RP, Hagen AA, Morgan H, Dawson WN, Robertson JT: Experimental study on the genesis of cerebral vasospasm. Stroke 6:52-57, 1975.

54. Winking M, Muller HW, Deinsberger W, Joedicke A, Boeker DK: Levels of immunoreactive cysteinyl-leukotrienes in CSF after subarachnoid haemorrhage correlate with blood-flow velocity in TDC. Acta Neurochir (Wien) 139:764-769, 1997.

55. Wittmann G, Peskar BM, Edelmann M, Muller KM, Simmet T, Peskar BA: Formation of cysteinyl-containing leukotrienes by human arterial tissues. Prostaglandins 33:591-598, 1987.

56. Yamamoto YL, Feindel W, Wolfe LS, Katoh H, Hodge CP: Experimental vasoconstriction of cerebral arteries by prostaglandins. J Neurosurg 37:385-397, 1972.

57. Yanamoto H, Kikuchi H, Okamoto S, Nozaki K: Cerebral vasospasm caused by cisternal injection of polystyrene latex beads in rabbits is inhibited by a serine protease inhibitor. Surg Neurol 42:374-381, 1994.

58. Yokota M, Tani E, Maeda Y, Kokubu K: Effect of 5-lipoxygenase inhibitor on experimental delayed cerebral vasospasm. Stroke 18:512-518, 1987.

59. Yoshimoto T, Yokoyama C, Ochi K, Yamamoto S, Maki Y, Ashida Y, Terao S, Shiraishi M: 2,3,5-Trimethyl-6(12-hydroxy-5,10dodecaniynyl)-1,4-benzoquinone (AA861), a selective inhibitor of the 5-lipoxygenase reaction and the biosynthesis of slow-reacting substance of anaphylaxis. Biochim Biophys Acta 713:470-473, 1982.

60. Young PR, Bell RL, Lanni C, Summers JB, Brooks DW, Carter GW: Inhibition of leukotriene biosynthesis in the rat peritoneal cavity. Eur J Pharmacol 205:259-266, 1991.

\section{COMMENTS}

The authors have evaluated a new selective 5-lipoxygenase inhibitor, ABT-761, in a rabbit model of subarachnoid hemorrhage (SAH). They demonstrated a reduction in the amount of vascular narrowing in treated animals. Arachidonic acid metabolism by the 5-lipoxygenase pathway produces leukotrienes, hydroxyperoxyeicosatetraenoic acid, and hydroxyeicosatetraenoic acid. Yokota et al. (1) showed angiographic evidence of reduced spasm after inhibition of 5-lipoxygenase in a canine model implicating this enzyme in the pathogenesis of cerebral vasospasm. Subsequent studies have suggested that the 5-lipoxygenase enzyme is absent in homeostatic conditions and is induced by $\mathrm{SAH}$, making this an attractive target for intervention. With this study and others reported in the literature, we agree with the authors that sufficient evidence exists to justify primate studies on the effect of 5-lipoxygenase inhibition for the treatment of cerebral vasospasm.

Warren R. Selman Christopher L. Taylor Cleveland, Ohio
1. Yokota M, Tani E, Maeda Y, Kokubu K: Effect of 5-lipoxygenase inhibitor on experimental delayed cerebral vasospasm. Stroke 18: 512-518, 1987.

The authors have demonstrated an antivasospastic action of an inhibitor of 5-lipoxygenase (ABT-761) in a rabbit model of SAH. The drug is reported to be a relatively specific inhibitor of this enzyme, although a demonstration of inhibition of the enzyme in the cerebral arteries of treated animals as compared with controls and of the lack of inhibition of similar but distinct enzymes would provide additional supportive evidence. Furthermore, a reduction in products of the enzyme and/or inflammation in the subarachnoid space would lead to more support for the authors' thesis that products of 5-lipoxygenase mediate vasospasm in this model. An excellent and comprehensive review of the literature followed that is constructed to support a role for altered eicosanoid metabolism and inflammation in the genesis of vasospasm. This reviewer thinks that such lipid mediators and free radical reactions are likely to be very important in the genesis of vasospasm, although the role of "inflammation" is unclear. There is a superficial resemblance between discussion of the role of inflammation in this article and its role in the pathogenesis of cerebral blood flow changes in bacterial meningitis (2). Inflammation is a complex biological response that may have beneficial and/or detrimental effects, depending, for example, on the specific type of inflammation that is induced and on the time after hemorrhage (1). As the complexity of these responses becomes clearer, the pathogenesis of vasospasm may as well.

R. Loch Macdonald Chicago, Illinois

1. Feuerstein GZ, Wang X, Barone FC: The role of cytokines in the neuropathology of stroke and neurotrauma. Neuroimmunomodulation 5:143-159, 1998.

2. Leib SL, Täuber MG: Pathogenesis of bacterial meningitis. Infect Dis Clin North Am 13:527-548, 1999.

Barbosa et al. have used their well-characterized rabbit model of SAH to examine the potential for a 5-lipoxygenase inhibitor (ABT-761) to diminish vasospasm after SAH. They have made several findings. The orally administered drug attains significant concentrations in the cerebrospinal fluid, and ABT-761 seems to diminish cerebral vasospasm at doses of $20 \mathrm{mg} / \mathrm{kg}$. The authors did not find a dose-dependent reduction in the vasospasm, indicating that this complex system may be affected in a biphasic way by the administration of the 5-lipoxygenase inhibitor. The discussion of this article regarding the multifaceted pathophysiology of cerebral vasospasm is quite instructive. The thoughtful discussion of this complex topic and the nicely controlled experiments presented here suggest that this pharmacological strategy may 
well be effective in attenuating cerebral vasospasm in human patients.

\section{Ralph G. Dacey, Jr. St. Louis, Missouri}

The cysteinyl leukotrienes $\mathrm{C}_{4}, \mathrm{D}_{4}$, and $\mathrm{E}_{4}$ are synthesized de novo from arachidonic acid via the activity of 5-lipoxygenase and a membrane-bound 5-lipoxygenase-activating protein (3). The effects of the cysteinyl leukotrienes are mediated via $\mathrm{Gq}$ protein-coupled receptors (5). Four major strategies have been followed in the search for drugs that inhibit the release or effects of the leukotrienes: phospholipase $A_{2}$ inhibitors, 5-lipoxygenase inhibitors, 5-lipoxygenase-activating protein inhibitors, and cysteinyl-leukotrienes receptor antagonists. Several potent and selective inhibitors of the first three classes of compounds have been identified and many of these have been in clinical trial for asthma treatment. Some of the 5-lipoxygenase inhibitors have shown impressive activity in clinical trials, which has highlighted the role of these mediators in asthma $(1,2)$. The 5-lipoxygenase inhibition has also been shown to be effective in both attenuating the synthesis of leukotrienes and in ameliorating cerebral vasospasm in the two-hemorrhage canine model $(4,6)$. The study presented here by Barbosa et al. provides further evidence for the effectiveness of the 5-lipoxygenase inhibitors in attenuating experimental cerebral vasospasm. In these studies, a novel and selective 5-lipoxygenase antagonist, ABT-761, administered once a day for 48 hours, was effective in attenuating vasospasm in a rabbit model of SAH. What is lacking that would make the hypothesis of the authors more appealing is a study of the levels of the leukotrienes and/or determination of 5-lipoxygenase activity in the cerebrospinal fluid that causally links the effects of ABT-761 to cerebral vasospasm. Furthermore, there is little relevance to the chronic cerebral vaso- spasm, which is maintained for several days. Obviously, further studies will be required to address these issues. Another important point is the authors' observation that ABT-761 seemed to be less effective when administered in a higher dose. One appealing possibility is that inhibition of 5-lipoxygenase activity with higher concentrations of the agent may increase the availability of the substrate arachidonic acid for cyclooxygenase action and the subsequent generation of vasoconstrictive products of this enzyme, thus contributing to the increase in vascular tone and diminished effectiveness of ABT-761. Certainly, ABT-761 efficacy in the treatment of chronic cerebral vasospasm must be addressed further before an optimistic conclusion is reached.

\section{J. Max Findlay Bozena Vollrath Pharmacologist Edmonton, Alberta, Canada}

1. Devillier P, Baccard N, Advenier C: Clinical studies with leukotriene receptor antagonists and leukotriene synthesis inhibitors in asthma. Pharmacol Res 40:15-29, 1999.

2. Devillier P, Baccard N, Advenier C: Leukotrienes, leukotriene receptor antagonists and leukotriene synthesis inhibitors in asthma. Pharmacol Res 40:3-13, 1999.

3. Ford-Hutchinson AW, Gresser M, Young RN: 5-Lipoxygenase. Annu Rev Biochem 63:383-417, 1994.

4. Kobayashi H, Ide H, Handa Y, Aradachi H, Arai Y, Kubota T: Effect of leukotriene antagonist on experimental delayed cerebral vasospasm. Neurosurgery 31:550-556, 1992.

5. Metters KM: Leukotriene receptors. J Lipid Mediat Cell Signal 12:4113-4127, 1995.

6. Yokota M, Tani E, Maeda Y, Kokubu KE: Effect of 5-lipoxygenase inhibitor on experimental delayed cerebral vasospasm. Stroke 18: 512-518, 1987.

\section{New Submission Guideline: Computer Diskette Required for All New Submissions}

To facilitate NEUROSURGERY's implementation of a dedicated online submission and review process, we are adding the following guideline, also found in the Instructions for Contributors:

MANUSCRIPT SUBMISSION. Send manuscripts (including all tables, illustrations, and references) in quadruplicate, all copy double-spaced with ample margins, to Michael L.J. Apuzzo, M.D., Editor, Neurosurgery, 1975 Zonal Ave., KAM 415, Los Angeles, CA 90033. A computer diskette copy of the manuscript text must be included with the hard copy. Incorrectly prepared manuscripts may result in delays in the review process and may be returned to the author(s) for corrections.

Thank you for your cooperation in submitting a computer diskette along with the copies of your manuscript. 